Review

\title{
Quantitative Measure of Sustainability for Water Distribution Systems: A Comprehensive Review
}

\author{
Seungyub Lee ${ }^{1(1)}$ and Joong Hoon Kim ${ }^{2, *}$ (i) \\ 1 Future and Fusion Lab, School of Civil, Environmental and Architectural Engineering, Korea University, \\ Seoul 02841, Korea; syl5894@korea.ac.kr \\ 2 School of Civil, Environmental and Architectural Engineering, Korea University, Seoul 02841, Korea \\ * Correspondence: jaykim@korea.ac.kr; Tel.: +82-2-3290-3316
}

Received: 12 November 2020; Accepted: 30 November 2020; Published: 3 December 2020

\begin{abstract}
This work provides a comprehensive review of the quantitative measures of sustainability proposed for water distribution systems (WDSs) and their sustainable development. After a comprehensive literature review, eighteen studies overall, either clearly proposing quantitative measures of sustainability (three studies) or highlighting sustainable development (fifteen studies), were selected for a closer review. All three measures showed either a lack of applicability or were missing important aspects of sustainability. Additionally, they have not been thoroughly validated by demonstrating the measures under acceptable scenarios/conditions. The reviewed sustainable development practices showed that energy usage and greenhouse gas emissions, life cycle costing, and reliability were widely used to evaluate environmental, economic, and social impacts, respectively. The two primary recommendations made based upon reviews were to: (1) consider balancing usage (cost) and gain (benefit), rather than impacts; (2) consider indirect (cascading/consequential) interactions. Overall, existing measures of sustainability and sustainable development practices in WDSs must be advanced to accommodate a focus on restorative systems, as well as to maximize benefits and enable multidisciplinary and broader analyses.
\end{abstract}

Keywords: water sustainability; sustainable development; water distribution system; drinking water infrastructure

\section{Introduction}

Drinking water infrastructure, which ensures the necessary supplies for daily water usage, is one of the most critical infrastructures in sustaining communities. However, the performance of the infrastructure inevitably degrades as it ages which is a pressing concerns to the water utilities [1-3]. Moreover, other challenges such as climate change, population growth, and resource limitations are also jeopardizing its performance and sustainability [4]. The American Society of Civil Engineers (ASCE) continuously issued D- and D grade of the Infrastructure Report Card for the drinking water infrastructure even though pipe replacement has been actively carried out to improve the performance of the infrastructure [1,2]. Such a process has been done in cost effective ways as the budget is limited [5-7]. In fact, Walski [8] emphasized that it is difficult to identify either true or net benefit (benefits minus costs) when cost minimization is used, especially in water distribution system (WDS) design, and it often results in such designs become self-fulfilling prophecies. Additionally, several reports have emphasized that cost minimization may result in long-term and broader impacts being overlooked [5,9-12]. Therefore, cost minimization cannot guarantee the sustainability of a system.

Since the publication of the Brundtland Commission's report in 1987 [13], the concept of sustainability or sustainable development for drinking water infrastructure has been widely referenced and studied by many researchers [14-16]. Sustainable development, as defined in this report, is a 
method to address the dilemma of advancing economic development while protecting environmental systems and enriching the quality of life for current and future generations [13]. This definition has been considered as a reference and revised according to specific contexts and applications $[17,18]$.

One of the most well-known approaches to sustainability rating practices is the Leadership in Energy and Environmental Design (LEED) method [19]. In this method, the sustainability features of a project are rated but are limited to measuring the sustainability of buildings. Another oft-used method is the Envision ${ }^{\mathrm{TM}}$ Rating System (Envision), developed by the Institute for Sustainable Infrastructure (ISI) and is a sustainability rating system for infrastructure systems. Envision rates the sustainability of infrastructure projects using a life-cycle analysis (LCA) approach, balances against community needs, and rewards restorative aspects of the infrastructure [20]. A research group at the University of Virginia also provided a sustainability rating framework for water supply systems by providing seven indicator categories [16]. These sustainability rating systems are often regarded as qualitative frameworks because some of the considerations need personal judgment and results may differ from person to person [21]. Qualitative frameworks are excellent tools but may result in subjective decisions [14] and their applicability to WDSs is uncertain.

Undeniably, sustainability is and will continue to be a critical criterion for WDS planning and management, but there is little agreement on the definition and quantitative criteria of sustainability or its improvement (i.e., sustainable development) [14-16,22]. Hence, this paper provides a comprehensive literature review of the existing WDS sustainability literature, as well as recommendations to address the aforementioned questions. The main objective of this study is to review the existing sustainability measures for WDS to provide opportunities to advance related research topics. Specifically, we summarize here how studies were selected from the literature for review, as well as their findings, before considering definition(s) and examples of sustainability, sustainable development, and how they are measured quantitatively. Finally, we identify the gaps that exist in the literature and provide recommendations for future studies to improve WDS sustainability.

\section{Review Methodology}

To ensure that this review was comprehensive, the Web of Science and Google Scholar were used for searching the relevant literature in a very extensive and wide array. These identified studies were then filtered by examining their titles, abstracts, and methodology to constrain the scope of the review to modeling and quantitative measures of the sustainability and sustainable development of WDSs. In the selected literature, studies that clearly proposed quantitative measures of sustainability and/or highlighted sustainable development were shortlisted after a closer review. Through this process, we selected eighteen studies overall, including three sustainability measures and fifteen sustainable development studies (Table 1). Note that all studies were published after the 2000s, even though publication time has not been customized. Table 1 summarizes why selected studies considered sustainability (problem to be solved), what was proposed as solution to solve the problem, and how selected studies quantified sustainability.

Table 1. Summary of problems considered, their proposed solutions, and the sustainability evaluation method of the selected literature.

\begin{tabular}{cccc}
\hline Reference & Problem & Proposed Solution & Evaluation \\
\hline Aydin et al. [23] & $\begin{array}{c}\text { Pressure deficit and } \\
\text { water age issue }\end{array}$ & Add booster pump & $\begin{array}{c}\text { Reliability, resilience, } \\
\text { and vulnerability }\end{array}$ \\
\hline Ramesh et al. [24] & Water scarcity & WDS design (rural) & $\begin{array}{c}\text { Measure of sustainability of } \\
\text { the system }\end{array}$ \\
\hline Lee and Burian [25] & Aging & NA & Triple top line \\
\hline
\end{tabular}


Table 1. Cont.

\begin{tabular}{|c|c|c|c|}
\hline Reference & Problem & Proposed Solution & Evaluation \\
\hline Filion et al. [26] & N/A & Pipe replacement & Life-cycle energy analysis \\
\hline Wu et al. [27] & Environmental impact & Pipe and pump design & $\begin{array}{l}\text { Life-cycle cost (LCC) and } \\
\text { greenhouse (GHG) emissions }\end{array}$ \\
\hline Wu et al. [28] & Environmental Impact & $\begin{array}{c}\text { Pipe and pump design and } \\
\text { tank location } \\
\text { determination }\end{array}$ & LCC and GHG emissions \\
\hline Wu et al. [29] & Environmental Impact & Pipe and pump design & $\begin{array}{l}\text { LCC, GHG emissions, and } \\
\text { carbon pricing }\end{array}$ \\
\hline Herstein et al. [30] & Environmental impact & Pipe and pump design & $\begin{array}{l}\text { LCC and Environmental } \\
\text { Impact Index }\end{array}$ \\
\hline Kang and Lansey [31] & Water supply shortage & $\begin{array}{c}\text { Dual water distribution } \\
\text { network }\end{array}$ & $\begin{array}{l}\text { LCC, GHG emissions, } \\
\text { and reliability }\end{array}$ \\
\hline Arif et al. [32] & Environmental impact & Pipe and pump design & $\begin{array}{l}\text { LCC and life-cycle emissions } \\
\text { with node pressures and } \\
\text { reliability constraints }\end{array}$ \\
\hline Nault and Papa [33] & $\begin{array}{l}\text { Inefficient energy } \\
\text { consumption } \\
\text { (pumping) }\end{array}$ & $\begin{array}{l}\text { Determine operational } \\
\text { practices }\end{array}$ & $\begin{array}{l}\text { LCA (net present value, LCC, } \\
\text { energy consumption, } \\
\text { GHG emissions) }\end{array}$ \\
\hline Lee and Burian [7] & Aging & Pipe replacement & Triple top line \\
\hline Lee et al. [34] & $\begin{array}{l}\text { Aging and insufficient } \\
\text { fund }\end{array}$ & User fee adjustment & Triple top line \\
\hline Koo and Ariaratnam [35] & NA & Pipe replacement & $\begin{array}{c}\text { Environmental impacts, } \\
\text { economic benefits and outputs, } \\
\text { social and cultural conservation } \\
\text { and promotion, and } \\
\text { structural soundness }\end{array}$ \\
\hline Farmani and Butler [36] & Urban planning & $\begin{array}{l}\text { WDS design with different } \\
\text { Urban form (layout) }\end{array}$ & $\begin{array}{l}\text { LCC, resilience, and water } \\
\text { quality (water age) }\end{array}$ \\
\hline Aydin et al. [37] & Water scarcity & $\begin{array}{l}\text { Reclaimed water for } \\
\text { non-potable water }\end{array}$ & $\begin{array}{l}\text { Reliability, resilience, } \\
\text { vulnerability, and } \\
\text { energy intensity }\end{array}$ \\
\hline Piratla [38] & Environmental Impact & Pipe and pump design & $\begin{array}{l}\mathrm{LCC} \text {, life-cycle } \mathrm{CO}_{2} \text { emissions, } \\
\text { resilience, and cost of reducing } \\
\mathrm{CO}_{2} \text { emission }\end{array}$ \\
\hline Cunha et al. [39] & $\begin{array}{l}\text { Uncertainties in future } \\
\text { scenario }\end{array}$ & Phase design (pipe design) & $\begin{array}{c}\text { Investment cost, } \mathrm{CO}_{2} \text { emissions, } \\
\text { and resilience/reliability }\end{array}$ \\
\hline
\end{tabular}

\section{Sustainability of Water Distribution Systems}

Among the various indicators of WDS performance, only those that quantify sustainability as a singular (or integrated) measure were selected for reviewing the quantification of sustainability. It is worthwhile to highlight that singular here implies the value is a representative value of sustainability that integrates multiple indicators or dimensions. Sustainable development was considered when it was clearly stated that a given work involved sustainable development and studies where surrogate measures (criteria) of sustainability were employed. Sustainable development often measures sustainability as a multidimensional measure rather than providing a singular measure. Here, we define the concept of "sustainability," review the measures used to quantify sustainability and briefly review the existing literature on sustainable development in the context of WDSs. 


\subsection{Defining Sustainability}

Sustainability or sustainable development has received much attention over the last few decades, yet there has been a lack of a general definition of "sustainability," as it has been applied to different systems with different objectives [22]. Therefore, we reviewed the various definitions of sustainability and identified their common features with respect to WDSs. We do not provide a general definition of sustainability, but rather provide a review of how it is commonly defined to aid in the conceptual understanding of "sustainability."

Loucks [40] defined sustainable water resource systems as the system satisfying social needs for now and in the future by maintaining ecological, environmental and hydrological integrity. Savic and Walters [41] emphasized that sustainability entails the minimum use of energy, loss of water, and number and consequences of pipe failures, as well as the most effective use of existing assets and meeting customers' needs in both quantity and quality as the basic criteria of a sustainable water supply system. Both Loucks [40] and Savic and Walters [41] highlighted the importance of the environment and performance of the infrastructure itself. However, Sahely et al. [42] more recently defined the sustainability of urban infrastructure as the provision of more efficient services that maintain public health and welfare, are cost-effective, and reduce negative environmental impacts both today and in the future. Thus, not only the environmental impact and performance but also the economic and social impacts, are included in this latter definition. These are generally defined as the three components of sustainability (i.e., the triple bottom line, TBL). The Resilient Sustainable Interdependent Infrastructures (RESIN) definition of sustainability is similar to that of Sahely et al. [42], and involves the ability to provide adequate and reliable water, energy, and material resource supplies of the desired quality (now and for future generations) in a manner that integrates economic well-being, environmental protection, and social needs [18].

The definition of sustainability for WDSs has been very limited. Lansey [18] divided the sustainability of WDS into two facets: water resources and infrastructure. Resource sustainability is the ability to continually provide adequate water supplies of acceptable quality without diminishing the long-term supply. Meanwhile, infrastructure sustainability is the ability of infrastructure to meet the resource sustainability goal with a minimum TBL impact. Furthermore, Lee [22] defined WDS sustainability as the ability to maintain performance for now and future generations by balancing usage and benefits in terms of economic, environmental, and social impacts. In summary, it is generally agreed that the definition of sustainability should consider the degree of satisfaction of the three components of sustainability (i.e., the economy, society, and environment), for both current and future generations. Therefore, economic, social, environmental, and temporal dimensions should be considered to understand and evaluate the sustainability of WDSs.

\subsection{Quantitative Measures of Water Distribution System Sustainability}

Even though sustainability has been discussed in many studies, a quantitative measure of sustainability for WDSs has been proposed in only three studies. Aydin et al. [23] proposed a sustainability index (SI) for WDSs by revising the SI introduced by Loucks [40]. Loucks [40] emphasized that minimizing risk and uncertainty will maximize sustainability and evaluated sustainability in terms of reliability, resilience, and vulnerability [43]. The SI is applied to water resource systems and can be quantified as follows:

$$
S I=R E L \times R E S \times(1-V U L)
$$

where REL is reliability, RES is resiliency, and VUL is vulnerability. The quantification of each of these criteria is based on the number of satisfactory and unsatisfactory performances during a given period, as shown in Table 2. 
Table 2. Summary of the quantitative measure of each criterion used to calculate the sustainability index (SI) proposed by Loucks [40].

\begin{tabular}{cc}
\hline Criterion & Equation \\
\hline Reliability & $R E L=\frac{\# \text { of times satisfactory occurs }}{\text { total \# of time steps }}$ \\
\hline Resiliency & $R E S=\frac{\# \text { of times satisfactory follows unsatisfactory }}{\text { total \# of times unsatisfactory occurs }}$ \\
\hline Vulnerability & $V U L=\frac{\sum \text { unsatisfactory values }}{\sum \text { all values }}$ \\
\hline
\end{tabular}

In Table 2, REL quantifies the probability of satisfactory state quantified for the total time period in consideration. RES considers recovery to a satisfactory state from the unsatisfactory state. It is also related to speed of recovery as it divides the number of recoveries from the unsatisfactory state by the total time period of unsatisfactory. In addition, VUL investigates the degree of an unsatisfactory state and its duration for a certain time scale.

The main revision to Loucks' [40] original SI by Aydin et al. [23] created ways to define system performance (i.e., satisfactory and unsatisfactory performance) suitable for WDSs. Additionally, Aydin et al. [23] considered SI as the geometric means of REL, RES, and VUL following Sandoval-Solis et al. [44]. To calculate REL, RES, and VUL, the nodal pressure and water age are considered to be the system performance, which are the results of hydraulic and water quality analyses using the EPANET2.0 [45]. Specifically, Aydin et al. [23] defined the minimum and maximum pressure per node and the maximum water age at each node. If the pressure and water age of a node are within the set limits, only then it is regarded as satisfactory. This calculation was performed per node and per time step. Aydin et al. [23] also divided WDSs into different zones based on geographic location. The SI quantified for each node was then aggregated based on their demand as follows:

$$
S I_{k, i}=\frac{\sum_{j=1}^{\text {nnodes }} D_{i, j} S I_{k, i, j}}{\sum_{j=1}^{\text {nnodes }} D_{i, j}}
$$

where $k$ is the performance in consideration, which is either pressure or water age, $i$ is the zone index, nnodes is the number of nodes, $D_{i, j}$ is the demand of the $j$ th node in $i$ th zone, and $S I_{k, i, j}$ is the pressure or water age SI of the $j$ th node in the $i$ th zone. The two SIs, pressure and water age, are considered and integrated using weights as follows:

$$
S I_{\text {overall }, i}=\sum_{k=1}^{n} w_{k, i} S I_{k, i}
$$

where $S I_{\text {overall }, i}$ is the overall SI of the $i$ th zone and $w_{k, i}$ is a normalized weighting factor for each SI (i.e., $\sum w_{k, i}=1$ ). Aydin et al. [23] applied equal weights for each SI by assuming that both pressure and water age are equally important. They also provided a standard to define the state of the system based on the range of SIs. The state was divided into four levels (i.e., unacceptable, moderate, acceptable, and ideal), the detailed ranges for which are shown in Table 3.

Table 3. Definitions of water distribution system (WDS) states based on the ranges of calculated SIs.

\begin{tabular}{cc}
\hline SI Range & State \\
\hline $0-0.25$ & Unacceptable \\
\hline $0.25-0.5$ & Moderate \\
\hline $0.5-0.75$ & Acceptable \\
\hline $0.75-1$ & Ideal \\
\hline
\end{tabular}


Ramesh et al. [24] constructed another quantitative measure of sustainability for WDS design. This was defined as a measure of system sustainability (SM), which is a function of the sustainability coefficient and adapted indices of effectiveness, as follows:

$$
S M=f(\text { Sustainability Coefficient, Adapted Indices of Effectiveness). }
$$

The sustainability coefficients include: (1) localization, (2) cost point, (3) overlap, (4) endurance, (5) loop, and (6) interaction coefficients. The localization coefficient explains the topographical area covered by a system and its interaction with the density of users. It considers the total network length function and the distance between various actors. Ramesh et al. [24] also divided the system into two main entities-actors and processes-with the actors including sources, pumps, storage, main networks, sub-networks, end taps, recharge, sensors, and communities; processes included the categorization of each actor by their functions-generation, transmission, distribution, and feedback. The cost point coefficient considers the cost associated with each process. The overlap coefficient evaluates the relationship among demand-and-supply-driven models by defining the number of users, normal water table level, water table level in summers, consumption rates, and the availability of energy sources. The endurance coefficient investigates the degree of a systems' reaction with various evaluation processes, while the loop coefficient quantifies the continuous flow of water and information in the system. The interaction coefficient is a function of community participation in the design, operation, and maintenance of the WDS, the number of activities performed, and the copying cost of water conservation. Each sustainability coefficient is normalized relative to the adaptive indices of effectiveness, which are summarized in Table 4. With the SM, Ramesh et al. [24] designed a WDS considering local community needs, the availability of labor, local resources, climate, cost, and time for implementation. The problem they focused on was water scarcity, especially in rural areas. However, they did not provide the details of their calculations.

Table 4. Adapted indices of effectiveness indicators (from Ramesh et al. [24]).

\begin{tabular}{|c|c|c|c|}
\hline $\begin{array}{l}\text { Sustainability } \\
\text { Indices }\end{array}$ & $\#$ & Indices of Effectiveness & Adapted Indices of Effectiveness \\
\hline \multirow{5}{*}{$\begin{array}{l}\text { Reliability and } \\
\text { Adequacy }\end{array}$} & 1 & $\begin{array}{c}\text { Percent of schemes supplying water as per } \\
\text { design norms (design norm of } 40 \text { lpcd or } \\
\text { more than } 40 \text { lpcd) }\end{array}$ & $\begin{array}{l}\text { Percent of households receiving } \\
\text { water as per design norm }\end{array}$ \\
\hline & 2 & $\begin{array}{l}\text { Percent of schemes supplying daily (at least } \\
\text { four hours of regular daily supply) }\end{array}$ & $\begin{array}{l}\text { Percent of households receiving } \\
\text { water at least } 12 \mathrm{~h} \text { per day }\end{array}$ \\
\hline & 3 & $\begin{array}{l}\text { Percent of schemes with households } \\
\text { spending less than } 30 \text { min per day in } \\
\text { collecting water }\end{array}$ & $\begin{array}{c}\text { Percent of households spending } \\
1<30 \text { min per day in } \\
\text { collecting water }\end{array}$ \\
\hline & 4 & $\begin{array}{l}\text { Percent of schemes with no major } \\
\text { breakdown in the past six months (a major } \\
\text { breakdown is defined as more than two } \\
\text { days of disruption in the water supply) }\end{array}$ & $\begin{array}{l}\text { Percent of pack with no major } \\
\text { breakdown in the past six months }\end{array}$ \\
\hline & 5 & $\begin{array}{l}\text { Percent of schemes with good water quality: } \\
\text { (i) no bacteriological contamination; (ii) no } \\
\text { chemical problems with arsenic, fluoride, } \\
\text { or salinity }\end{array}$ & $\begin{array}{l}\text { Percent of households with good } \\
\text { water quality: (i) no } \\
\text { bacteriological contamination; } \\
\text { (ii) no chemical problems with } \\
\text { arsenic, fluoride, or salinity }\end{array}$ \\
\hline
\end{tabular}


Table 4. Cont.

\begin{tabular}{|c|c|c|c|}
\hline $\begin{array}{l}\text { Sustainability } \\
\text { Indices }\end{array}$ & \# & Indices of Effectiveness & Adapted Indices of Effectiveness \\
\hline \multirow{2}{*}{$\begin{array}{c}\text { Financial } \\
\text { Sustainability }\end{array}$} & 6 & $\begin{array}{l}\text { Percent of schemes with }>80 \% \text { operation \& } \\
\text { maintenance (O\&M) cost recovery }\end{array}$ & $\begin{array}{l}\text { Percent monthly collection with } \\
\quad>60 \% \text { O\&M cost recovery }\end{array}$ \\
\hline & 7 & $\begin{array}{l}\text { Percent of schemes with }>80 \% \\
\text { collection efficiency }\end{array}$ & $\begin{array}{l}\text { Percent of households with }>80 \% \\
\text { collection efficiency }\end{array}$ \\
\hline \multirow{3}{*}{ Affordability } & 8 & $\begin{array}{l}\text { Water tariff for household connections as a } \\
\text { ratio of rural per capita income }\end{array}$ & $\begin{array}{l}\text { Percentage of households with } \\
>80 \% \text { contribution efficiency }\end{array}$ \\
\hline & 9 & $\begin{array}{l}\text { Water tariff for stand post users (shared } \\
\text { connections) as a ratio of rural per } \\
\text { capita income }\end{array}$ & $\begin{array}{l}\text { Household water tariff as a ratio } \\
\text { of household income }\end{array}$ \\
\hline & 10 & $\begin{array}{l}\text { Percent of schemes with }>50 \% \\
\quad \text { household connections }\end{array}$ & $\begin{array}{l}\text { Percentage of water taps utilized } \\
\text { for more than } 6 \mathrm{~h} \text { a day }\end{array}$ \\
\hline \multirow{2}{*}{$\begin{array}{l}\text { Environmental } \\
\text { Sustainability }\end{array}$} & 11 & $\begin{array}{l}\text { Percent of schemes with a source providing } \\
\quad>80 \% \text { yield (as per design norms) }\end{array}$ & $\begin{array}{l}\text { Percentage of months the energy } \\
\text { tariffs exceed design norms }\end{array}$ \\
\hline & 12 & NA & $\begin{array}{l}\text { Percentage of toilets using the } \\
\text { water supplied under the scheme }\end{array}$ \\
\hline
\end{tabular}

Lee and Burian [25] also developed a measure of sustainability by focusing purely on quantification and proposed an SI for WDSs based on the triple top line (TTL) method, which was introduced by McDonough and Braungart [46] and has been a beneficial tool for assessing sustainability according to business agendas. It is a similar method to the TBL approach in that it considers coincident sustainability components (Figure 1); however, it considers beneficial aspects rather than impacts (or costs). TTL-based sustainable development typically aims to reduce, re-use, and recycle, creating "more goods and services while using ever-less resources and producing less waste and pollution." In other words, the TTL approach tends to maximize benefits and minimize costs (or impacts), while TBL only focuses on minimizing impacts.

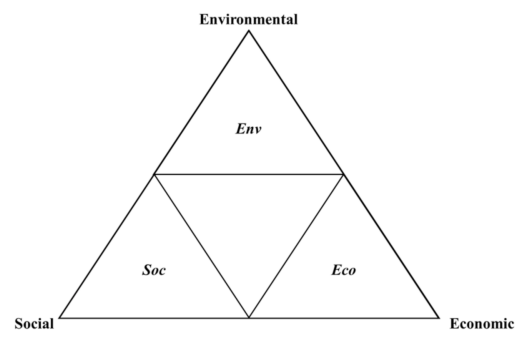

(a)

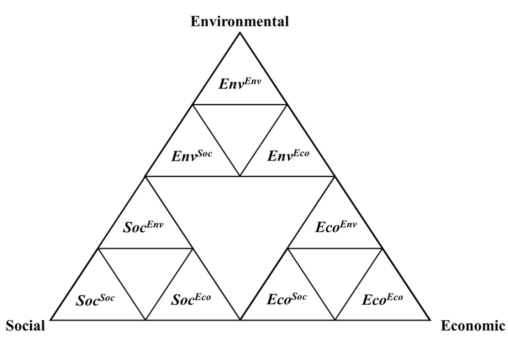

(b)

Figure 1. Schematic showing the factors considered in (a) triple bottom line (TBL) and (b) triple top line (TTL) measures of sustainability.

Another difference between the TBL and TTL methods is that the latter considers the relationships between different sustainability components. Figure 1 illustrates the configuration of both the TBL and TTL models. The TBL approach is composed of three triangles (or factors), while the TTL model has nine (three for each sustainability component). The attributes of the triangles between two sustainability components (e.g., $E c O^{S o c}, E c o^{E n v}$, and so on) are determined based on the relationships between them. These triangles consider the adjacent components' (what each triangle is adjacent to; shown as a superscript) problems from the perspective of the primary sustainability component. For example, $E c O^{S o c}$ views social problems from an economic perspective; Lee and Burian [25] defined this as a customer's affordability. All triangles are quantified as the ratio between benefits (including recycled) 
and consumption. Table 5 summarizes the approach used to calculate each triangle shown in Figure 1 and detailed calculation examples can be found in [25].

Table 5. Calculations and descriptions for each WDS TTL factor.

\begin{tabular}{|c|c|c|}
\hline Factor & Calculation * & Description \\
\hline$E c o^{E c o}$ & $\mathrm{Eco}^{E c o}{ }_{t}=\frac{\sum P_{i, t}}{\sum C_{t}}$ & Economic benefit cost ratio \\
\hline$E c o^{S o c}$ & $\mathrm{Eco}^{\mathrm{Soc}_{t}}=\frac{\sum E C L I P S_{i, t} \times Q_{d e l, i, t} \times B I}{\sum P_{i, t}}$ & Economic consequence benefit (customer's affordability) \\
\hline$E c O^{E n v}$ & $\mathrm{Eco}^{E n v}{ }_{t}=\frac{\sum Q_{\text {del }, i, t}-\sum E\left(Q_{\text {leak }, i^{*}, t}\right)}{\sum Q_{\text {sup }, t, t}}$ & Water efficiency \\
\hline Soc Eco & $\operatorname{Soc}_{t}^{E c o}=1-2 G_{w, t}$ & Social consequence benefit (equity) \\
\hline Soc ${ }^{\mathrm{Soc}}$ & $\operatorname{Soc}^{S{ }^{\prime} c}=\frac{\sum Q_{\text {req }, i t} \times U_{i, t}(c)}{\sum Q_{\text {req }, i, t}}$ & Reliability (quantity/quality) \\
\hline Soc Env & $\operatorname{Soc}^{E n v}{ }_{t}=\frac{\sum\left(\left(R_{t, j} / R_{n e v, j}\right) \times A_{w, j}\right)}{\sum A_{w, j}}$ & Structural efficiency (system age) \\
\hline$E n v^{S o c}$ & $\mathrm{Env}_{t} \mathrm{Soc}_{t}=\frac{\sum(\mathrm{GHG})_{\mathrm{red}, t}}{\sum(\mathrm{GHG})_{g e n, t}}$ & Environmental consequence benefit (GHG emission) \\
\hline$E n v^{E n v}$ & Env $^{E n v}{ }_{t}=\frac{\sum E_{\text {gen }, t}+\sum E_{r e m, t}}{\sum E_{\text {sup }, t}}$ & Environmental impact \\
\hline$E n v^{E c o}$ & $\operatorname{Env}^{E n v}{ }_{t}=\frac{\sum\left(Q_{\text {del }, i} \times h_{i, t}\right)}{\sum\left(Q_{\text {sup }, i, t} \times h_{i, t}\right)}$ & Energy efficiency \\
\hline
\end{tabular}

* Variables: $A_{w, j}=$ water flow area of $j$ th pipe $\left(\mathrm{m}^{2}\right) ; \mathrm{BI}=$ burdensome index; $C_{t}=$ required cost, including construction, operation, and maintenance for all components of the WDS at time $t(\$) ; E_{g e n, t}=$ generated energy at time $t(\mathrm{~J})$; $E_{r e m, t}=$ amount of remaining energy in the system at time $t(\mathrm{~J}) ; E_{\text {sup }, t}=$ supplied (required) energy resource at time $t$ (J); $E\left(Q_{\text {leak }, i, t}\right)=$ expected water leakage at $i$ th leakage location at time $t\left(\mathrm{~m}^{3}\right) ; E C L I P S_{i}=$ economic outcome $i$ th node $\left(\$ / \mathrm{m}^{3}\right) ; G_{w, t}=$ water Gini coefficient at time $t ; h_{i, t}=$ head at $i$ th node at time $t(\mathrm{~m}) ; i=1, \ldots$, nnodes $=$ number of nodes; $j=1, \ldots$, nlink $=$ number of links; $P_{i, t}=$ revenue of $i$ th node at time $t(\$) ; Q_{\text {del }, i, t}=$ delivered water demand (demand of EPANET) at $i$ th node at time $t\left(\mathrm{~m}^{3}\right) ; Q_{\text {req, }, i t}=$ required water demand (base demand of EPANET) at $i$ th node at time $t\left(\mathrm{~m}^{3}\right) ; Q_{\text {sup }, i, t}=$ supplied water demand from $i$ th node at time $t\left(\mathrm{~m}^{3}\right) ; R_{t, j}$ and $R_{\text {new }, j}=$ roughness of the $j$ th pipe at time $t$ and when new $(\mathrm{t}=0) ; U_{t, i}(c)=$ combined utility of $i$ th node at time $t$.

Economic factors (triangles in Figure 1) investigate the value to the utility, customer, and environment by the WDS service, where $E c 0^{E c o}$ is the value of the water utility, which is the ratio of revenue (mainly from a bill) and associated costs (e.g., from construction, operation, maintenance, etc.). Thus, a higher $E c 0^{E c o}$ will be achieved by lower O\&M costs or increasing revenues by adjusting the price of water. Furthermore, $E c 0^{S c c}$ is related to $E c 0^{E c o}$, but considers the affordability of the water price to customers, which is calculated using the ECLIPS factor introduced by Lee et al. [47] and Lee et al. [48], with consideration of the burdensome index (BI). Unlike $E c 0^{E c o}$, Eco ${ }^{S o c}$ increases when the water price is low and the economic status of customers rises; $E c 0^{E n v}$ considers the efficiency of the WDS and evaluates the ratio between the total water delivered and supplies (or billing if data is sufficient). In other words, Eco ${ }^{E n v}$ estimates water leakage and can be improved once the leaks in a system are reduced.

Social factors are used to evaluate the distribution of benefits around the service area of the WDS. For example, $S o c^{E c o}$ considers the social consequences benefit, which is the equity calculated by the Lorenz curve and Gini coefficient of water. For $S o c^{E c o}$, equity in the distribution of pressure is a goal and can be improved by regulating pressure, while $S o c^{S o c}$ reflects the reliability of the WDS, which is calculated using demand, pressure, and water quality, as proposed by Shafiqul Islam et al. [49]. Therefore, improving $S o c^{S o c}$ is possible once demand, pressure, and water quality are at acceptable levels. Finally, $S o c^{E n v}$ considers the structural efficiency of the system according to its age, as represented by the pipe size and length of weighted pipe roughness, which reflect the average age of the system and can be improved by performing maintenance.

Environmental factors consider the resource usage or environmental impacts of WDS service. For example, $E n v^{E c o}$ quantifies energy efficiency and aims to estimate the amount of avoided 
energy losses from system failure. Lee and Burian [25] adapted the concept of resilience to reflect efficiency [50,51], which can be increased when energy loss is minimized. The environmental benefits are considered to be represented by the ratio between the amount of greenhouse (GHG) emissions reduced and those generated for the $E n v^{S o c}$ factor. Thus, $E n v^{S o c}$ can be improved by reducing GHG emissions (e.g., less fabrication of assets, more usage of renewable energy, and more water usage in green areas). Moreover, $E n v^{E n v}$ considers energy usage and benefits using a life-cycle energy analysis (LCEA) approach [52]. Energy benefit is quantified as the energy generated (e.g., by in-line turbine or pump-as turbine) or available stored energy (e.g., in nodes or tanks).

The nine triangles of the TTL schematic (Figure 1) are combined into an SI measure of WDSs. This SI is determined by calculating the geometric mean of the TTL factors:

$$
S I_{t}=\left(\prod T T L_{f}\right)^{1 / 9}
$$

where $T T L_{f}$ is each TTL factor (e.g., $E c 0^{E c o}, E c o^{S o c}, E c 0^{E n v}$, etc.) and $S I_{t}$ is the measure of sustainability of the WDS in the $t$ th year, where the average $S I_{t}$ over time provides the $S I$ for the analytical period:

$$
S I=\int_{t=1}^{L C} S I_{t} d t / L C
$$

and $L C$ is the duration (in years) of the life cycle or planning period. In contrast to the other studies reviewed, Lee and Burian [25] tested the TTL model with solutions to those issues having generally understandable trends in sustainability; for example, pipe aging is negatively correlated with sustainability. As a result, the aging of pipes, increase in water demand, reduction in water prices, and increase in the frequency of pipe breakage reduced sustainability.

\subsection{Sustainable Development of Water Distribution Systems}

Here, we summarize sustainable development examples from selected studies, including the quantitative measures and approaches employed therein. Examples are divided into three categories based on their consideration: (1) environmental impacts, (2) TBL objective, and (3) multi-objective. The first category includes studies that only considered environmental impacts. Research considering economic, social, and environmental objectives are included in the second category, and any other studies with multiple objectives in one sustainability component are classified into the third category. Each study is reviewed to answer three questions: (1) why selected studies considered sustainability (problem to be solved), (2) what was proposed as solution to solve the problem, and (3) how selected studies quantified sustainability.

\subsubsection{Environmental Impact Objective}

As most of the existing literature highlights the need for sustainable development with respect to climate change and resource depletion, there have been some attempts to account for environmental impacts induced by WDS operations and maintenance. WDSs require energy to operate (e.g., electricity for pumps), which is associated with GHG emissions [53-55]. Furthermore, even the fabrication of components requires energy (i.e., embodied energy) and resources [26]. A few studies have highlighted this aspect and considered it as the single-objective that must be minimized for sustainable WDS design. All types of energy consumption contribute to GHG emissions. Therefore, researchers have emphasized the importance of the energy-efficient operation and management of WDSs to reduce GHG emissions and minimize environmental impacts.

Filion et al. [26] proposed the LCEA approach, which estimates the embodied energy of a pipe and any associated energy for WDS operation in order to consider its environmental impacts for the purpose of sustainable design. The LCEA is based on the EIO-LCA model developed by the Green Design Institute [56]. A summary of the LCEA approach is shown in Table 6. 
Table 6. Quantitative measure of each embodied energy.

\begin{tabular}{|c|c|c|}
\hline \multicolumn{2}{|c|}{ Factor } & Calculation \\
\hline \multicolumn{2}{|c|}{ Fabrication Energy } & $E_{f}=\sum_{i}^{p} L_{i} e_{f}$ \\
\hline \multirow{4}{*}{ Maintenance Energy } & Replacement Energy & $E_{\text {rep }}=n_{i, r e p} \cdot \sum_{i}^{p} L_{i}\left(e_{f}+e_{d}\right)$ \\
\hline & Rehabilitation Energy & $E_{r h}=n_{i, r h} \cdot \sum_{i}^{p} L_{i}\left(R \cdot e_{f}\right)$ \\
\hline & Repair Energy & $E_{r p}=C_{r p} \cdot \sum_{i}^{p} L_{i} \cdot N_{i}(t) \cdot e_{b, i}$ \\
\hline & Recycle Energy & $E_{r c}=\sum_{i=1}^{p}\left(E_{P, i}^{r}-E_{P, i}^{s}\right)$ \\
\hline \multicolumn{2}{|c|}{ Disposal Energy } & $E_{d}=\sum_{i}^{p} L_{i} e_{d}$ \\
\hline
\end{tabular}

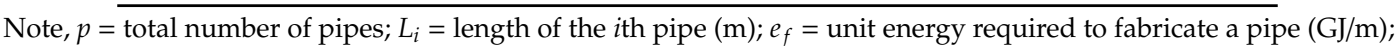
$e_{d}=$ unit energy required to dispose of a pipe $(\mathrm{GJ} / \mathrm{m}) ; n_{i, r e p}=$ replacement frequency of the $i$ th pipe during the simulation period; $n_{i, r h}=$ rehabilitation frequency of the $i$ th pipe during the simulation period; $R=$ rehabilitation ratio; $C_{r p}=$ unit conversion factor $\left(\mathrm{km} / \mathrm{m} /\right.$ year); $e_{b, i}=$ unit energy required to repair the $i$ th pipe $(\mathrm{GJ} / \mathrm{break}) ; E_{P, i}^{r}=$ energy required for the $i$ th pipe under rough conditions; $E_{P, i}^{s}=$ energy required for the $i$ th pipe under smooth conditions.

Information regarding the unit energies and calculation examples can be found in previous studies, including [26,52]. In contrast, Pérez-Sánchez et al. [57] reviewed energy recovery practices in a WDS, rather than minimizing energy usage or GHG emissions; this was a data-driven analysis, but energy recovery was concluded to be a sustainable solution by showing an improved, system-wide energy efficiency. Moreover, Pérez-Sánchez et al. [57] showed that energy recovery can be an economic solution even if it depends on the orography, topology, and volume of water consumed in the WDS. In summary, environmental impacts have generally been quantified based on energy usage and GHG emissions following such usage.

\subsubsection{Triple Bottom Line Objective}

As TBL objectives are considered important under the definition of "sustainability," they have garnered extensive interest in sustainability assessments. The TBL approaches tend to minimize the impacts on economic, social, and environmental sustainability components. For example, Wu et al. [27] created an optimal WDS design to minimize both GHG emissions and costs as a multi-objective problem. For GHG emissions, they considered not only GHG emissions due to the usage of electricity but also the embodied energy [26]. In their follow-up study [28], they explored the trade-offs between cost and GHG emission objectives and showed that less cost will increase the amount of GHG emission. They also showed the sensitivity of discount rates to final decisions, similar to that which Simpson [58] noted. However, Simpson [58] highlighted the importance of having an accurate discount rate, as sustainability measures tend to analyze performance over a long time and require present values to be estimated based on the discount rate. More recently, Wu et al. [29] added a carbon pricing component into their earlier model [28].

Herstein et al. [30] considered both life-cycle cost (LCC) and an environmental impact index for WDS design. In contrast to other studies, they aggregated three different categories of indices into a single measure and defined it as the environmental impact index. The three index categories were resource consumption (nonrenewable energy use), environmental discharges (air pollutants, toxic releases into the air, water, and land), and environmental impacts (ecological fossil fuel footprint), and each category included several measured indices. Evaluating the environmental impact index starts by evaluating the measure indices. Once these are quantified, the categorical indices are computed as averages of the measured indices. Finally, the environmental impact index is determined by assigning 
stakeholder weights for each category. Herstein et al. [30] applied the environmental impact index with LCC to design WDSs; as a result, the pumping cost was found to be a major contributor to increasing both the total cost and environmental impact, while pipe cost did not significantly affect the total cost or environmental impacts, but did significantly influence pumping costs.

Kang and Lansey [31] utilized a TBL approach to support decision-making for dual distribution system planning. Economic impacts were considered to include pure capital and the O\&M costs of pipes and pumps. For environmental impacts, GHG production was considered, and the GHG emissions from manufacturing (i.e., embodied energy) to production, due to pump operation, were covered. Finally, system reliability was considered to quantify the social impact and the evaluation of sustainability was solved as a multi-objective problem. Note that system reliability is the percentage of total demand delivered to customers which calculated as the ratio between serviced demand and total demand. For each impact, the maximum values were used to normalize each objective function within $0-1$. Kang and Lansey [31] concluded that a dual water distribution network could improve sustainability.

Arif et al. [32] considered LCC and life cycle emissions as an objective function while constraining reliability (>0.8) [59]. LCC includes capital, operational, maintenance, and repair costs, and the present net value (PNV) is applied to all costs except for capital costs. Life-cycle emissions include three stages: fabrication, installation, and operation. Data for estimating emissions were collected from multiple studies [60-62]. Reliability has been quantified based on breakage probability following [59]. Arif et al. [32] designed a WDS by determining the pump characteristic curves and pipe diameter and concluded that LCC alone is not sufficient to achieve a sustainable design.

Nault and Papa [33] presented a methodology that combined a process-based LCA with an EIO-LCA model to quantify the PNV LCC, energy consumption, and GHG emissions associated with a WDS pump. Operating factors, such as control via discharge valve throttling, pump deterioration, and refurbishment, were also considered. The sustainability measures of interest were PNV LCC (measured in \$USD), gross energy consumption (measured in GWh), and GHG emissions produced $\left(\mathrm{t}-\mathrm{CO}_{2}\right.$-eq). The results showed that a combination of refurbishment and variable-speed pumping was the most effective means of improving sustainability.

Lee and Burian [7] and Lee et al. [34] present examples of TTL applications for the sustainable development of WDSs. In both studies, the aging problem of WDSs was noted. Lee and Burian [7] determined optimal pipe replacement and demand management strategies to improve the TTL of a WDS. Their results showed that sustainable solutions tend to replace pipes earlier than economic ones, and both higher and lower demand changes were ultimately unsustainable. However, the total cost of the sustainable solution was greater than that of the economic solution; therefore, increases in user fees were recommended to compensate for the increased total cost. Lee et al. [34] provided a solution to recover the increased total cost by increasing user fees. For this, they constructed a hybrid system dynamics (H-SD) model and analyzed the interconnections among different factors affecting sustainability. Water price elasticity was added to account for the social response to increased water fees. As a result, frequent increases with lower water price increases in rates were preferred for the higher water price elasticity system (i.e., sensitive to changes in water price).

In summary, there have been several studies that were purely focused on the components of sustainability in which researchers aimed to minimize impacts or maximize the benefits of each component to develop a sustainable WDS.

\subsubsection{Multi-Objective}

The many-objective problems of sustainability enhancement have been demonstrated in some studies by including the three pillars of sustainability, as well as other components (e.g., resilience, water quality, and structural soundness). For example, Koo and Ariaratnam [35] developed a multi-criterion sustainability evaluation tool, the sustainability assessment model (SAM), which considers four objectives for enhancing sustainability: (1) minimizing environmental impact, (2) maximizing economic 
benefits and outputs, (3) social and cultural conservation and promotion, and (4) satisfying basic requirements, such as structural soundness and capacity. Such objectives were evaluated using six modules that took both qualitative and quantitative approaches. The first module was an analytic hierarchy process, which assessed twenty-nine sustainability indicators; these were qualitative and divided into economic, environmental, and social aspects. The second module was a real cost estimation module. The real cost considered individual economic impacts, including detailed direct construction and indirect costs (e.g., restoration, social costs, and environmental remediation costs). The third and fourth modules were focused on pollution and energy estimations and both were related to air emissions (GHG emissions) as a consequence of fossil energy consumption. Each module accounted for the generation of pollution and energy consumption. The fifth module was a time estimation module, which treated the length of construction time as a reflection of economic, environmental, and social impacts. The last module was a resource depletion analysis, which focused on nonrenewable natural resource consumption and the estimated depletion rates of such resources. Once these six modules had assessed sustainability, a weighted sum model was utilized to integrate the results.

Farmani and Butler [36] investigated the performance of a WDS with different urban forms (compact/uniform, monocentric, polycentric, and edge development), in which each urban form represented different socioeconomic scenarios. For each form, the total cost, resilience [63], and water quality were evaluated for different urban growth rates to identify the most sustainable form of development. A multi-objective optimization problem was constructed following Farmani et al. [64] except that water quality (water age) was considered. With the model, pipe sizing, pump design and operation, and tank characteristics were determined, and they concluded that an accurate growth forecast and associated demand are important for determining the capacity of a system to manage supply and demand. Meanwhile, Aydin et al. [37] applied the methodology proposed by Aydin et al. [23] to investigate both the technical and environmental sustainability of a WDS using reclaimed water to meet the non-potable water demand. Technical sustainability was evaluated using their earlier methodology [23] while environmental sustainability was calculated according to the energy intensity, which is the total energy consumption of a network divided by the total energy requirement. Trade-offs between technical and environmental sustainability were then identified by simple additive weighting.

Piratla [38] described the increased interest in growing carbon emissions and the scarcity of renewable energy in sustainability, along with resilience. In this regard, they considered three objectives (LCC, life-cycle $\mathrm{CO}_{2}$ emissions [62,65], and resilience [66]) to optimally design a WDS to achieve sustainability and resilience. Additionally, design solutions were investigated with respect to social benefit, which was evaluated by the cost of reducing $\mathrm{CO}_{2}$ emissions $\left(\$ 20 /\right.$ ton $\mathrm{CO}_{2}$ emission). To that end, Piratla [38] concluded that solutions with lower $\mathrm{CO}_{2}$ emissions may have higher costs, but this will payout throughout the life cycle by counting the cost of reducing $\mathrm{CO}_{2}$ emissions. Cunha et al. [39] also highlighted that sustainable solutions should take into consideration a wide range of possible future scenarios as noted by Loucks [40]. Furthermore, Cunha et al. [39] considered four dimensions in their study: economic, environmental, reliability, and societal. These dimensions were quantified by investment cost, carbon emissions, and resilience/reliability. Investment costs were estimated by considering the PNV, and only the carbon emissions of the pipe were considered based on the methodology proposed by Marques et al. [67]. For resilience, a minimum generalized resilience/failure index [68] was considered, and loop diameter uniformity [69] was considered as an indirect measure of reliability. Most importantly, Cunha et al. [39] adopted a phase design to account for uncertainties in future scenarios. The future scenarios considered included pipe aging (initial Hazen-Williams coefficient of 130 and reduced by 2.5 per decade), and demand scenarios were based on variations per phase. They considered four phases, including current time (i.e., year $=0$ ) and each phase was 25 years in length; thus, Phase 2 began in year 25, and so on. For each phase, different demand variations were given to proportion to the base demand (e.g., demand in Phase 1), and constant changes of a 25\% 
increase in the maximum variation per phase or a $5 \%$ decrease in the minimum variation per phase were employed.

\section{Discussion and Recommendations}

In general, the need for sustainability has been widely agreed upon. However, no consensus on the definition or evaluation of sustainability has been reached. Therefore, we considered the issues identified from sustainability indices and measures and sustainable development applications in the literature to develop recommendations for improving WDS sustainability.

\subsection{Quantitative Measures of Water Distribution System Sustainability}

Overall, two SIs and one SM were identified to measure the sustainability of WDSs. Here, we compare these measures from three different aspects: (1) ease of application, (2) interpretation of the final value(s), and (3) validation of the measure. For the sake of simplicity, the SI proposed by Aydin et al. [23] is denoted as "SI_Aydin," and that proposed by Lee and Burian [25] is denoted as "SI_Lee."

In terms of the ease of application, SI_Aydin has an advantage over other methods as it only requires EPANET input files, while both SM and SI_Lee require specific data. Thus, other measures are site-specific and difficulties may arise when applying them to different networks, though this also indicates that SI_Aydin might provide limited information about the sustainability of a given WDS. Nevertheless, SI_Aydin can be improved by adding additional performance and its satisfactory and unsatisfactory states, which would also require a new direction to compute the SI in Equation (2). For example, if considering economic performance, budgetary constraints may be set and the SI defined as 1 when the total cost is less than the budgetary constraint; otherwise, it is computed as a ratio of the budgetary constraint to the actual cost. In this case, the weights to calculate the overall SI in Equation (3) should be defined. Regarding SM, some of the indicators $(1,4,11$, and 12) may involve personal judgments, as their exact boundaries are unclear. Moreover, some of the indicators $(2,3$, $5,7,8,9$, and 10) require too much detailed information, which brings the acquisition of sufficient data into question. Furthermore, SI_Lee also requires detailed data, such as that from ECLIPS, which needs to classify each demand node with an appropriate NAICS code that might not be available for different networks. However, this issue can be overcome if customers' income information is available (i.e., ECLIPS is unnecessary if affordability can be estimated using a different approach).

The common feature missing from all sustainability measures was a clear interpretation of the final result. Evaluating sustainability levels involves new and emerging criteria; it is often difficult to identify the maximum and minimum values or thresholds with which to define a system as sustainable or unsustainable [70]. As SM did not provide a specific example, it is unclear how the sustainability state might be determined under this approach. Each criterion of SI_Lee is a ratio of a benefit to a cost, so a value of 1 indicates a break-even point, but further details (e.g., threshold to define sustainability) besides this information were not given. However, SI_Lee used the variation of SI in different timesteps to assess the trends of changes in the SI and identify whether a system was sustainable or unsustainable. Only SI_Aydin provided a sustainability state based on the SI_Aydin range (Table 3). Even though it is given roughly, this type of systemized interpretation helps in understanding the sustainability state of a system. However, this is still an issue. SI_Aydin is based on the methodology of Loucks [40] whose method was based on the assumption that less risk is better for sustainability. While this may provide a good representative of sustainability for the current state, it is uncertain whether the performance will be retained in the future. In other words, it is missing the important sustainability characteristics of "now and (in) future generations." Therefore, there is no evidence that a higher SI_Aydin magnitude will lead to higher values of sustainability in the future. 
The last and most important step in demonstrating that a proposed measure can provide reliable conclusions is validation. In fact, most of the sustainability measures proposed lacked this step, rendering their conclusions doubtful. Rodríguez López and Fernández Sánchez [70] mentioned that this is mainly the result of a short history of sustainability evaluations. Therefore, there is insufficient data to judge whether a certain scenario or condition may be sustainable or not. Neither the SI_Aydin nor SM approaches included this step, while an attempt was made to validate SI_Lee with known-as unsustainable scenarios (e.g., aging, demand increase, etc.). Even though Lee and Burian [25] tried to validate their method and provide a graphical representation with which to identify sustainable and unsustainable states, this has not been tested in different systems or under different conditions/scenarios. To provide a generalized measure, more tests should be conducted. Additionally, the uncertainties of parameters should be discussed, as Simpson [58] and Wu et al. [28] noted that some time-dependent parameters (e.g., discount rate) are highly sensitive to the final results.

In summary, all three sustainability measures showed room for improvement. First, as the general definition agreed on consideration of all three sustainability components, it is important to consider all components to provide a holistic view. Second, validation of the sustainability measure with acceptable scenarios/conditions is in need to improve the reliability of the final results. In addition, this will help to provide a reference for determining states of sustainability depending on its value. Lastly, the downscaling of final results to the criteria level is required to identify weakness (i.e., low criteria). The SI may provide a different graphical tool, such as a spider or radar diagram that expresses the valuation of a project or alternative in relation to each indicator or dimension, to solve the problem.

\subsection{Sustainable Development of Water Distribution Systems}

In general, most of the sustainability measures and sustainable development studies considered resource depletion and climate change. From this perspective, many tended to consider the environmental impacts of the sustainable development of WDSs. The most common ways to consider environmental impacts are based on energy usage and GHG emissions. The economic component is also an uncontroversial part, as LCC is a traditional approach for planning and managing WDSs. The social component was the least-considered component of sustainability. However, reliability has been actively selected when considered. There have been some considerations in addition to sustainability components, such as resilience and water quality. As sustainability is usually considered for a longer duration, most of the studies considered the life cycle of the WDS of interest.

One interesting trend captured was that most studies were focused on minimizing impacts. This is important but it has a limitation in that minimizing impacts does not always translate into maximum benefits [8]. Returning to the definition of sustainability, the key issue is the satisfaction of sustainability components now and for future generations. Reflecting on this, the main focus should be on achieving a balance between usage (costs) and gain (benefits), not just minimizing usage, so the future generation can at least start at a similar starting point. However, minimizing impacts is often the focus of end-of-pipe initiatives in which negative effects are managed to produce fewer adverse outcomes. For example, new technologies might have higher implementation costs, which will lead to higher economic impacts at a glance, but the other benefits might outweigh the economic impacts [15]. In this simple example, a strategy focused purely on minimizing impacts will likely not implement the new technology because it cannot identify the other benefit. Likewise, while there is nothing wrong with such an approach, minimizing the negative effects (minimizing impact/usage part) will simply slow ecological destruction without mitigating it (maximizing benefit/gain part). Moreover, this approach can obscure opportunities to pursue innovation and create value in the design process by limiting economic constraints. Thus, quantitative measures of sustainability must evolve to focus on restorative and regenerative systems, and not simply seek to minimize impacts; for example, they should consider the balance between usage and gain rather than the usage alone. 
Another limitation to the existing literature is that the majority of sustainability measures only take direct interactions into account from the water utility perspective, although the communities that receive water also have indirect (cascading/consequential) interactions [71-73]. Neglecting these consequential interactions and minimizing impacts may result in WDS designs that simply repeat the history of environmental degradation that emerged from the industrial revolution [74], and may lead to solutions being less innovative $[15,46]$. As Lansey [18] indicated, sustainability can have two different definitions: (1) infrastructure and (2) resource. Evaluating the continuous service of a WDS to support social activities by transporting environmental resources is "infrastructure sustainability," which most sustainability measures consider; on the other hand providing continuous support from social and environmental resources for WDS service is "resource sustainability." A lack of resource sustainability may lead to false sustainability by assuming that resources are always refilling (e.g., a WDS in a shrinking city). Thus, WDS sustainability should include both infrastructure (WDS) and resource sustainability by identifying interactions among all stakeholders, not just from a utility perspective.

\section{Conclusions}

Multiple challenges may jeopardize the performance of WDSs even though sustainability has become an important criterion for their planning and management. This paper comprehensively reviews the current status of quantitative measures of sustainability proposed for WDSs and sustainable development practices therein. Overall, three sustainability measures and fifteen sustainable development studies were selected for review.

By comparing three sustainability measures, three important requirements of sustainability measures have been identified. First, sustainability measures should consider all components to provide a holistic view. Second, sustainability measures should be validated with acceptable scenarios/conditions and provide a sustainability state depends on its value. Lastly, the downscaling of final results to the criteria level is required to identify weakness (i.e., low criteria).

Environmental impacts and economic components were the most popular considerations for defining sustainable development in the literature reviewed. In most cases, energy usage and GHG emissions were used to evaluate environmental impacts, while LCC was utilized to quantify the economic component. For social impacts, reliability was widely selected. Additionally, LCA was implicitly considered to investigate levels of sustainability, as it generally involves longer simulation periods. Though they were not considered as major criteria, resilience and water quality were also evaluated in a few studies. One interesting trend captured was that most studies were focused on minimizing impacts such that they may slow (but not stop) ecological destruction. Instead, we recommend that a balance between usage (costs) and gain (benefits) be considered in future studies. Finally, indirect (cascading/consequential) interactions were also needing to be considered. As the justification for the existence of a WDS is the prosperity of the community, interactions among all stakeholders must be identified to move toward sustainable development. In summary, existing quantitative measures of WDS sustainability and sustainable development practices require advancement to accommodate a focus on restorative systems, maximize benefits, and enable multidisciplinary and broader analyses.

Author Contributions: Conceptualization, S.L.; methodology, S.L.; formal analysis, S.L.; investigation, S.L.; writing-original draft preparation, S.L.; writing-review and editing, S.L. and J.H.K.; visualization, S.L.; supervision, J.H.K.; project administration, J.H.K.; funding acquisition, J.H.K. All authors have read and agreed to the published version of the manuscript.

Funding: This research and APC was funded by the Ministry of Science and ICT of the Republic of Korea, grant number 2019R1A2B5B03069810, and by the National Research Foundation of Korea, grant number 2019R1A2B5B03069810.

Conflicts of Interest: The authors declare no conflict of interest. 


\section{References}

1. ASCE. 2013 Report Card for America's Infrastructure; American Society of Civil Engineers: Reston, VA, USA, 2013.

2. ASCE. 2017 Report Card for America's Infrastructure; American Society of Civil Engineers: Reston, VA, USA, 2017.

3. Williams, W.; Jones, M.; Stillman, J. Asset management: How US utilities can leverage international experience. J. Am. Water Work. Assoc. 2013, 105, 86-91. [CrossRef]

4. USEPA. Moving Toward Sustainability: Sustainable and Effective Practices for Creating Your Water Utility Roadmap; United States Environmental Protection Agency: Washington, DC, USA, 2014.

5. Kettler, A.J.; Goulter, I.C. An analysis of pipe breakage in urban water distribution networks. Can. J. Civ. Eng. 1985, 12, 286-293. [CrossRef]

6. ASCE. Failure to Act: Closing the Infrastructure Investment Gap for America's Economic Future; American Society of Civil Engineers: Reston, VA, USA, 2016.

7. Lee, S.; Burian, S. Triple top line-based identification of sustainable water distribution system conservation targets and pipe replacement timing. Urban Water J. 2019, 16, 642-652. [CrossRef]

8. Walski, T.M. The wrong paradigm-Why water distribution optimization doesn't work. J. Water Resour. Plan. Manag. 2001, 127, 203-205. [CrossRef]

9. Tlili, Y.; Nafi, A. A practical decision scheme for the prioritization of water pipe replacement. Water Supply 2012, 12, 895-917. [CrossRef]

10. Rogers, P.D.; Grigg, N.S. Failure assessment modeling to prioritize water pipe renewal: Two case studies. J. Infrastruct. Syst. 2009, 15, 162-171. [CrossRef]

11. D'Ercole, M.; Righetti, M.; Raspati, G.S.; Bertola, P.; Maria Ugarelli, R.M. Rehabilitation planning of water distribution network through a reliability-Based risk assessment. Water 2018, 10, 277. [CrossRef]

12. Kanakoudis, V.K. Vulnerability based management of water resources systems. J. Hydroinformatics 2004, 6, 133-156. [CrossRef]

13. Brundtland Commission. Our Common Future: World Commission on Environment and Development; Hauff, V., Ed.; Oxford University Press: Oxford, UK, 1987.

14. Papajohn, D.; Brinker, C.; El Asmar, M. MARS: Metaframework for assessing ratings of sustainability for buildings and infrastructure. J. Manag. Eng. 2016, 33, 04016026. [CrossRef]

15. Taddune, G. A permanent seat at the table: The role of sustainability in the boardroom. J. Am. Water Work. Assoc. 2018, 110, 55-58. [CrossRef]

16. Richter, B.D.; Blount, M.E.; Bottorff, C.; Brooks, H.E.; Demmerle, A.; Gardner, B.L.; Herrmann, H.; Kremer, M.; Kuehn, T.J.; Kulow, E.; et al. Assessing the sustainability of urban water supply systems. J. Am. Water Work. Assoc. 2018, 110, 40-47. [CrossRef]

17. ASCE. Policy Statement 418: The Role of the Civil Engineer in Sustainable Development; American Society of Civil Engineers: Renton, VA, USA, 2004.

18. Lansey, K. Sustainable, robust, resilient, water distribution systems. In Proceedings of the WDSA, 14th Water Distribution Systems Analysis Conference, Adelaide, SA, Australia, 24-27 September 2012; p. 1.

19. USGBC. Leadership in Energy and Environmental Design LEED; United States Green Building Council: Washington, DC, USA, 2007.

20. ISI. Envision: Driving Success in Sustainable Infrastructure Projects; Institute for Sustainable Infrastructure: Washington, DC, USA, 2018; Available online: http://sustainableinfrastructure.org/envision/ (accessed on 11 October 2020).

21. Lee, S. Triple Top Line-Based Asset Management Analysis Approach to Enhance Sustainability of Water Distribution Systems. Ph.D. Thesis, The University of Utah, Salt Lake City, UT, USA, 2019.

22. Werkheiser, I.; Piso, Z. People work to sustain systems: A framework for understanding sustainability. J. Water Resour. Plan. Manag. 2015, 141, A4015002. [CrossRef]

23. Aydin, N.Y.; Mays, L.; Schmitt, T. Sustainability assessment of urban water distribution systems. Water Resour. Manag. 2014, 28, 4373-4384. [CrossRef] 
24. Ramesh, M.; Mohan, R.; Kumar, M.N.; Brahmanandan, D.; Prakash, C.; Lalith, P.; Kumar, M.A.; Ramkrishnan, R. Micro water distribution networks: A participatory method of sustainable water distribution in rural communities. In Proceedings of the 2016 IEEE Global Humanitarian Technology Conference GHTC, Seattle, WA, USA, 13-16 October 2016; pp. 797-804.

25. Lee, S.; Burian, S. Triple top line-based sustainability measure for water distribution systems. J. Infrastruct. Syst. 2020, 26, 04020027. [CrossRef]

26. Filion, Y.R.; MacLean, H.L.; Karney, B.W. Life-cycle energy analysis of a water distribution system. J. Infrastruct. Sys. 2004, 10, 120-130. [CrossRef]

27. Wu, W.; Simpson, A.R.; Maier, H.R. Multi-objective Genetic Algorithm Optimisation of Water Distribution Systems Accounting for Sustainability. In Proceeding of Water down under 2008; Lambert, M., Daniell, T.M., Leonard, M., Eds.; Engineers Australia/Causal Productions: Modbury, SA, Australia, 2008; pp. 1750-1761. Available online: https://search.informit.com.au/documentSummary;dn=588665181983343;res=IELENG (accessed on 1 December 2020).

28. Wu, W.; Simpson, A.R.; Maier, H.R. Accounting for greenhouse gas emissions in multiobjective genetic algorithm optimization of water distribution systems. J. Water Resour. Plan. Manag. 2009, 136, 146-155. [CrossRef]

29. Wu, W.; Maier, H.R.; Simpson, A.R. Single-objective versus multiobjective optimization of water distribution systems accounting for greenhouse gas emissions by carbon pricing. J. Water Resour. Plan. Manag. 2010, 136, 555-565. [CrossRef]

30. Herstein, L.; Filion, Y.; Hall, K. Evaluating environmental impact in water distribution system design. J. Infrastruct. Syst. 2009, 15, 241-250. [CrossRef]

31. Kang, D.; Lansey, K. Dual water distribution network design under triple-bottom-line objectives. J. Water Resour. Plan. Manag. 2011, 138, 162-175. [CrossRef]

32. Arif, M.; Syal, M.; Piratla, K.R.; Ariaratnam, S.T. Design innovation leads to sustainable water distribution systems. Constr. Innov. 2013, 13, 302-319.

33. Nault, J.; Papa, F. Lifecycle assessment of a water distribution system pump. J. Water Resour. Plan. Manag. 2015, 141, A4015004. [CrossRef]

34. Lee, S.; Pomeroy, C.; Burian, S. Setting future water rates for sustainability of a water distribution system. J. Water Resour. Plan. Manag. 2020. [CrossRef]

35. Koo, D.-H.; Ariaratnam, S.T. Application of a sustainability model for assessing water main replacement options. J. Constr. Eng. Manag. 2008, 134, 563-574. [CrossRef]

36. Farmani, R.; Butler, D. Implications of urban form on water distribution systems performance. Water Resour. Manag. 2014, 28, 83-97. [CrossRef]

37. Aydin, N.Y.; Mays, L.; Schmitt, T. Technical and environmental sustainability assessment of water distribution systems. Water Resour. Manag. 2014, 28, 4699-4713. [CrossRef]

38. Piratla, K.R. Investigation of sustainable and resilient design alternatives for water distribution networks. Urban Water J. 2016, 13, 412-425. [CrossRef]

39. Cunha, M.; Marques, J.; Creaco, E.; Savić, D. A dynamic adaptive approach for water distribution network design. J. Water Resour. Plan. Manag. 2019, 145, 04019026. [CrossRef]

40. Loucks, D.P. Quantifying trends in system sustainability. Hydrol. Sci. J. 1997, 42, 513-530. [CrossRef]

41. Savic, D.A.; Walters, G.A. Evolving sustainable water networks. Hydrol. Sci. J. 1997, 42, 549-564. [CrossRef]

42. Sahely, H.R.; Kennedy, C.A.; Adams, B.J. Developing sustainability criteria for urban infrastructure systems. Can. J. Civ. Eng. 2005, 32, 72-85. [CrossRef]

43. Hashimoto, T.; Stedinger, J.R.; Loucks, D.P. Reliability, resiliency, and vulnerability criteria for water resource system performance evaluation. Water Resour. Res. 1982, 18, 14-20. [CrossRef]

44. Sandoval-Solis, S.; McKinney, D.; Loucks, D. Sustainability index for water resources planning and management. J. Water Resour. Plan. Manag. 2010, 137, 381-390. [CrossRef]

45. Rossman, L.A. EPANET2: Users Manual; U.S. Environmental Protection Agency: Washington, DC, USA, 2000.

46. McDonough, W.; Braungart, M. Design for the triple top line: New tools for sustainable commerce. Corp. Environ. Strateg. 2002, 9, 251-258. [CrossRef]

47. Lee, S.; Shin, S.; Judi, D.; McPherson, T.; Burian, S. Water distribution system recovery strategies considering economic consequences from business loss. In Proceedings of the CCWI2017, 15th International Computing \& Control for the Water Industry Conference, Sheffield, UK, 5-7 September 2017. 
48. Lee, S.; Shin, S.; Judi, D.R.; McPherson, T.; Burian, S.J. Criticality analysis of a water distribution system considering both economic consequences and hydraulic loss using modern portfolio theory. Water 2019, 11, 1222. [CrossRef]

49. Shafiqul Islam, M.; Sadiq, R.; Rodriguez, M.J.; Najjaran, H.; Hoorfar, M. Reliability assessment for water supply systems under uncertainties. J. Water Resour. Plan. Manag. 2013, 140, 468-479. [CrossRef]

50. Shin, S.; Lee, S.; Judi, D.R.; Parvania, M.; Goharian, E.; McPherson, T.; Burian, S.J. A systematic review of quantitative resilience measures for water infrastructure systems. Water 2018, 10, 164. [CrossRef]

51. Jayaram, N.; Srinivasan, K. Performance-based optimal design and rehabilitation of water distribution networks using life cycle costing. Water Resour. Res. 2008, 44, W01417. [CrossRef]

52. Lee, S.; Yoo, D.G.; Jung, D.; Kim, J.H. Application of life cycle energy analysis for designing a water distribution network. Int. J. Life Cycle Assess. 2017, 23, 1174-1191. [CrossRef]

53. Dandy, G.; Roberts, A.; Hewitson, C.; Chrystie, P. Sustainability objectives for the optimization of water distribution networks. In Proceedings of the WDSA, 8th Annual Water Distribution Systems Analysis Symposium, Cincinnati, OH, USA, 27-30 August 2006; pp. 1-11.

54. Simpson, A. How to account for sustainability in the design and operation of water distribution systems. In Proceedings of the World City Water Forum, Songdo Convensia, Incheon, Korea, 18-21 August 2009; pp. 279-286.

55. Roshani, E.; Filion, Y. Water distribution system rehabilitation under climate change mitigation scenarios in Canada. J. Water Resour. Plan. Manag. 2014, 141, 04014066. [CrossRef]

56. Green Design Institute. Economic Input-Output Life Cycle Assessment (EIO-LCA): US 2002 Industry Benchmark Model; Carnegie Mellon University: Pittsburgh, PA, USA, 2008; Available online: http://www.eiolca.net/ Models/USmodels/US02ProducerPrice.html (accessed on 9 November 2020).

57. Pérez-Sánchez, M.; Sánchez-Romero, F.J.; Ramos, H.M.; López-Jiménez, P.A. Energy recovery in existing water networks: Towards greater sustainability. Water 2017, 9, 97. [CrossRef]

58. Simpson, A.R. Selecting a discount rate for evaluating water distribution projects-The sustainability controversy. In Proceedings of the WDSA, 10th Water Distribution Systems Analysis Conference, Kruger National Park, South Africa, 17-20 August 2008; pp. 1-12.

59. Su, Y.-C.; Mays, L.W.; Duan, N.; Lansey, K.E. Reliability-based optimization model for water distribution systems. J. Hydraul. Eng. 1987, 113, 1539-1556. [CrossRef]

60. Ambrose, M.; Salomonsson, G.; Burn, S. Piping Systems Embodied Energy Analysis. CMIT Doc. 2; CSIRO Manufacturing and Infrastructure Technology: Highett, VIC, Australia, 2002; p. 302.

61. Ariaratnam, S.T.; Sihabuddin, S.S. Comparison of emitted emissions between trenchless pipe replacement and open cut utility construction. J. Green Build. 2009, 4, 126-140. [CrossRef]

62. Piratla, K.R.; Ariaratnam, S.T.; Cohen, A. Estimation of $\mathrm{CO}_{2}$ emissions from the life cycle of a potable water pipeline project. J. Manag. Eng. 2011, 28, 22-30. [CrossRef]

63. Todini, E. Looped water distribution networks design using a resilience index based heuristic approach. Urban Water 2000, 2, 115-122. [CrossRef]

64. Farmani, R.; Walters, G.A.; Savic, D.A. Trade-off between total cost and reliability for Anytown water distribution network. J. Water Resour. Plan. Manag. 2005, 131, 161-171. [CrossRef]

65. Piratla, K.R.; Ariaratnam, S.T. Reliability based optimal design of water distribution networks considering life cycle components. Urban Water 2012, 9, 305-316. [CrossRef]

66. Prasad, T.D.; Park, N.-S. Multiobjective genetic algorithms for design of water distribution networks. J. Water Resour. Plan. Manag. 2004, 130, 73-82. [CrossRef]

67. Marques, J.; Cunha, M.; Savić, D.A. Using real options for an eco-friendly design of water distribution systems. J. Hydroinform. 2015, 17, 20-35. [CrossRef]

68. Creaco, E.; Franchini, M.; Todini, E. Generalized resilience and failure indices for use with pressure-driven modeling and leakage. J. Water Resour. Plan. Manag. 2016, 142, 04016019. [CrossRef]

69. Creaco, E.; Franchini, M.; Todini, E. The combined use of resilience and loop diameter uniformity as a good indirect measure of network reliability. Urban Water 2016, 13, 167-181. [CrossRef]

70. Rodríguez López, F.; Fernández Sánchez, G. Challenges for sustainability assessment by indicators. Leadersh. Manag. Eng. 2011, 11, 321-325. [CrossRef]

71. Cole, J.; Sharvelle, S.; Fourness, D.; Grigg, N.; Roesner, L.; Haukaas, J. Centralized and decentralized strategies for dual water supply: Case study. J. Water Resour. Plan. Manag. 2017, 144, 05017017. [CrossRef] 
72. Brown, E.; Ternieden, C.; Metchis, K.; Beller-Simms, N.; Fillmore, L.; Ozekin, K. Emergency response or long-term resilience? Extreme events challenge water utilities and their communities. J. Am. Water Work. Assoc. 2013, 105, 38-40. [CrossRef]

73. Linhoss, A.; Jeff Ballweber, J. Incorporating uncertainty and decision analysis into a water-sustainability index. J. Water Resour. Plan. Manag. 2015, 141, A4015007. [CrossRef]

74. Lodder, M.; Huffenreuter, R.L.; Braungart, M.; den Held, D. Regenerative sustainable development: Towards a triple top line approach and increasing positive externalities. In Proceedings of the 5th International Sustainability Transitions Conference, Sustainability Transitions Research Network, Utrecht, The Netherlands, 27-29 August 2014; pp. 27-29.

Publisher's Note: MDPI stays neutral with regard to jurisdictional claims in published maps and institutional affiliations.

(C) 2020 by the authors. Licensee MDPI, Basel, Switzerland. This article is an open access article distributed under the terms and conditions of the Creative Commons Attribution (CC BY) license (http://creativecommons.org/licenses/by/4.0/). 